\title{
Generating chlorine dioxide for third world water purification
}

\author{
Manoj Mistry* and Stephanie Moore \\ Department of Chemical and Biomolecular Engineering, University of Melbourne, Australia \\ *manoj.mistry@hotmail.co.uk
}

\begin{abstract}
Chlorine dioxide has been proven to be more effective in deactivating viruses and holds a number of advantages over other disinfection methods such as preventing trihalomethane (carcinogenic) formation whilst eliminating harmful pathogens such as Giardia. There are 3.41 million deaths per year in less economically developed countries due to pathogenic diseases in their water supply. Therefore, a simple electrolysis setup was explored using readily available chemicals, with the aim of implementing this practical disinfection method in third world countries. This research proposes that chlorine dioxide can be economically produced by the electrolysis of sodium chloride solution. Attempts to stabilise chlorine dioxide, due to its sensitivity to disproportionate, were explored via the addition of sodium bicarbonate. From conducting a series of electrolysis experiments, the conditions that permit the production of chlorite/chlorate were identified to be: a maximum current density of $1 \mathrm{~A} / \mathrm{dm}^{2}$, dissimilar electrode materials and a large amount of sodium chloride, $\sim 30 \mathrm{wt} \%$. It was also concluded that a higher oxidation potential was essential for producing the desired chlorine dioxide. Additions of sodium bicarbonate proved useful in controlling the $\mathrm{pH}$ but caused complications in analysis, further investigations are required into when and how much should be added. Optimisation of the variables identified in this research could unlock the operating conditions required to successfully produce chlorine dioxide via this inexpensive method.
\end{abstract}

KEYWORDS: Chlorine Dioxide, Disinfection, Electrolysis, Less Economically Developed Countries (LEDC), Sanitation.

The World Health Organisation (WHO) and the North Atlantic Treaty Organisation (NATO) have been carefully following the world population increase and have predicted that by 2025 the population will have increased to 8.9 billion - the maximum population the planet's water supply can sustain (White, 1999). The majority of the population increase is occurring in Less Economically Developed Countries (LEDCs), which in greater parts is due to lack of birth control/family planning, coupled with an increase in life expectancy (White, 1999). Whilst an increase in water usage occurs in LEDCs, the water usage remains relatively constant in More Economically Developed Countries (MEDCs); even though a larger portion of the world's water budget is used by MEDCs. The reason for LEDCs not using the same amount of water relative to their population is because they lack access to clean water (Rodgers, 2002). At times where no sanitary water is available to people in economically deprived countries, they have been left with no choice but to use water contaminated with human/animal waste and toxic chemicals for drinking or recreational purposes which contributes to a rate of 3.41 million deaths per year in LEDCs (Ustun, 2008).

The waterborne microorganisms associated with contaminated water include a number of bacteria and protozoa, which result in various infectious diseases and as a consequence, a vast number of fatalities. The protozoan parasite entamoeba histolytica which causes the disease amoebiasis is the third leading cause of death after malaria and tuberculosis. This and other prevalent water-transmitted pathogens namely legionella, cryptosporidium, cholerae and giardia lamblia, have enormous impact in developing countries (Haque, 2007).

There have been numerous water and sanitation projects implemented in LEDCs by international banks and aid organisations. Unfortunately, the failure rate of implemented systems outnumbers the success rate. The reason for this is that these systems were narrowly based on engineering and technical considerations from developed countries, which were then limited by a lack of infrastructure and resources (Lonholdt, 2005). Bearing in mind that 
climate conditions can play a factor in mutations / variations of waterborne viruses (Feachem, 1977), this implies that some different infectious agents are present in tropical climates (most LEDCs) that may not be present in less tropical latitudes. Evidently, treatment of contaminated water in LEDCs has to be planned, designed and implemented so that the local circumstances are incorporated throughout the project life cycle, thus allowing inhabitants of developing countries the possibility to access reliable potable drinking water sustainably and effectively.

This project explored an economical water disinfection process that could be practically employed in LEDCs.

\section{WATER DISINFECTION}

Water disinfection can be accomplished in a number of ways, the essential mechanism being some form of disruption to the pathogenic cell's normal function. In the developed world, disinfection via chemical agents is most commonly used in water treatment to remove undesirable levels of contaminants, i.e. pathogens and any trace inorganic materials such as iron and manganese, as well as for taste and odour control. Introducing chemical agents to the developing world, as opposed to physical and mechanical methods of water treatment (e.g. boiling and sand filtration), would be beneficial due to its increased efficacy in eliminating a wide variety of waterborne pathogens.

The typical chemical agents used for disinfection are chlorine or ozone. Chlorine is not only cheap but has a number of well-established advantageous characteristics including fast reaction rates and residual disinfection, which gives the confidence of pathogen-free treated water. Ozone is the most reactive due to its high oxidising strength making it the most potent biocide. On the other hand, ozone leaves no residual disinfection (Hoff \& Geldreich, 1980). A major disadvantage shared by both agents, is the tendency to produce carcinogenic by-products such as trihalomethanes (THMs) (Amundsen, 1980). Chlorine dioxide $\left(\mathrm{ClO}_{2}\right)$ has been found to be a suitable alternative as it exhibits strong biocidal effects and minimises the formation of harmful byproducts whilst providing a sufficient amount of residual disinfection (Hoehn et al, 1996).

\section{CHLORINE DIOXIDE}

$\mathrm{ClO}_{2}$ was first used in water treatment processes in the United States (U.S.) at Niagara Falls in 1944 (Amundsen, 1980). Eighty-four water treatment plants using this chlorine compound were set up by 1977 in the U.S with many more making the switch in Europe. Another use found for $\mathrm{ClO}_{2}$ was the replacement of chlorine as a bleaching agent for chemical pulp in the paper industry in the late 1980s (Vogt et al, n.d.); this was due to the environmental drawbacks such as from using elemental chlorine.

The properties and reaction kinetics of $\mathrm{ClO}_{2}$ make it highly suitable as a water disinfectant. It exists as a highly volatile free radical monomer with a boiling point of $11{ }^{\circ} \mathrm{C}$ and is typically gaseous at room temperature. It has a yellow colour with a distinctive pungent odour; however, when dissolved in water, its colour varies from a pale yellow to a distinctive dark green solution depending on the concentration.

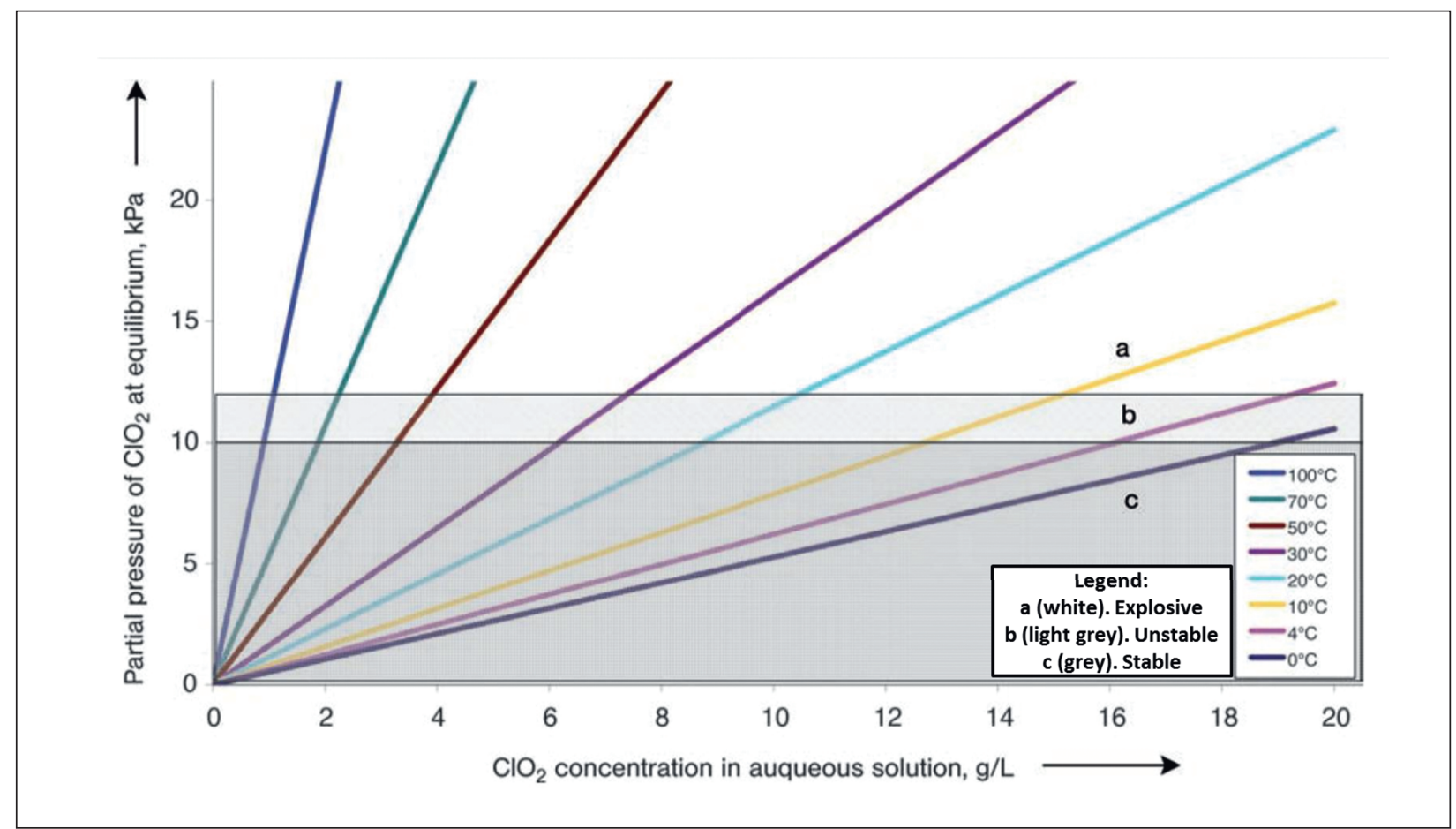

Figure 1: Chlorine dioxide stability as a function of partial pressure and concentration; a. Explosive, b. Unstable, c. Stable (Vogt et al, n.d.). 
One of the critical characteristics of $\mathrm{ClO}_{2}$ is its high solubility, although this decreases with increasing temperature. This allows for flexible generation in the aqueous or gaseous form, depending on the desired end mode of application.

The efficient biocidal activity of $\mathrm{ClO}_{2}$ is accomplished due to its high selectivity. This is because it has a characteristic single electron exchange mechanism via which it attacks the electron-dense centres in organic molecules and can effectively inactivate parasites including those which are resistant to chlorine. This difference in its deactivation mechanism makes it unsusceptible to microbial resistant mutations (Hoehn et al, 1996).

In reactions between $\mathrm{ClO}_{2}$ and organic compounds, such as humic acids, the carbon-carbon bonds are generally not broken down and no addition of chlorine to the organic molecule can take place, hence THM formation is minimised (Gordon et al, 1972). $\mathrm{ClO}_{2}$ also reacts with many inorganic species, such as manganese (II) and iron (II), thus removing them from solution (Csordas et al, 2001). Furthermore, $\mathrm{ClO}_{2}$ reacts with phenolic compounds, making it excellent at eliminating odours and tastes associated with trace phenolics in solution (Gates, 1998).

\subsection{Safety \& storage}

$\mathrm{ClO}_{2}$ is a gas at room temperature and can be easily detected by its pungent smell, even at very low concentrations. Inhalation of this chemical can be very irritating to the respiratory system and also to the eyes. Continued inhalation and exposure can cause: flooding tears, coughing, headache, nausea, nasal discharge, wheezing and bronchitis. Long-term exposure leads to pulmonary oedema, which can show up hours after exposure (NAP, 2007).

Chlorine dioxide is explosive under pressure if the partial pressure exceeds $10.1 \mathrm{kPa}$ or at high concentration (Figure 1) and as a result of this, $\mathrm{ClO}_{2}$ is not commercially available due to safety and economics concerns (Vogt et al, n.d.). $\mathrm{ClO}_{2}$ cannot be compressed and storage of the chemical is not advised; it is also never shipped. At gaseous concentrations that exceed $10 \%$ by volume in air, $\mathrm{ClO}_{2}$ may spontaneously explode and it has an ignition temperature of approximately $130{ }^{\circ} \mathrm{C}$ (EPA, 1999).

However, $\mathrm{ClO}_{2}$ solutions at concentrations below $9 \mathrm{~g} / \mathrm{L}$ and at room temperature conditions do not produce vapour pressures high enough to present any real threat. In the water treatment industry, $\mathrm{ClO}^{2}$ is used at low concentrations in water and the temperature is highly unlikely to exceed $40{ }^{\circ} \mathrm{C}$, thus the conditions to cause concerns are unlikely to be met (EPA, 1999).

At neutral or acidic $\mathrm{pH}$ levels, $\mathrm{ClO}_{2}$ in solution is stable for long periods of time if it is stored at low concentrations (1 wt \%) in the dark and at cool temperatures with no headspace. $\mathrm{ClO}_{2}$ exposed to a light source, i.e. sunlight, can quickly disproportionate to either chlorite or chlorate due to thermal and photochemical decomposition (Gates, 1998). This disproportionation can also occur in basic solutions (greater than $\mathrm{pH}$ 9) where $\mathrm{ClO}_{2}$ breaks down into chlorite and chlorate.

\subsection{Stabilised chlorine dioxide}

Thorough research has also gone into trying to manufacture what is known as stabilised chlorine dioxide (SCD), the concept of which is still not fully understood. This was first developed by BioCide International to solve the issues of stability and volatility associated with this species (Junli et al, 2001). It is believed to be a salt form of $\mathrm{ClO}_{2}$ in solution which is adhered to a carbonate complex and can remain stable for long periods of time; however, some believe that in reality this is simply a readily available stable chlorite species and no unanimous decision has been reached. This 'stabilised' form can then be activated upon initial contact with the waterborne pathogens, causing destabilisation, making it a highly efficient commercial product. There are three requirements for conditions to produce this stable compound, namely: the manufacture of the compound in solution, basic conditions and a carbonate complex for stabilisation purposes (Junli et al, 2001).

\subsection{Manufacture}

There are many types of systems that water treatment companies offer to produce $\mathrm{ClO}_{2}$. Some of these are: reactors that produce $\mathrm{ClO}_{2}$ via catalytic reactions, resins that can be easily regenerated consisting of reactants that produce $\mathrm{ClO}_{2}$ and generators based on acid reduction of chlorate that are built into water supply pipes that release $\mathrm{ClO}_{2}$ according to online monitoring of water quality. There are also various electrolysis methods that use semi-permeable membranes and/or a cocktail of chemicals that include buffers, $\mathrm{ClO}_{2}$ precursors and acids. There are also portable packaged tablets and powdered forms of SCD available in the markets that are generally designed for disinfecting a small amount (e.g. 1 litre) of untreated water.

However, none of the mentioned methods are applicable to LEDCs as the systems are too complex for local populations to easily operate and maintain. The tablet and powdered forms would require continuous supply to the LEDCs or manufacturing plants built in close proximity to the local communities, adding further complications. Although electrolysis has been found to only require $1.2 \mathrm{~V}$ for $\mathrm{ClO}_{2}$ generation and seems plausible if its operation can be adapted for simple use in LEDCs (Pourbaix, 1974). The use of a membrane would be costly and require constant 


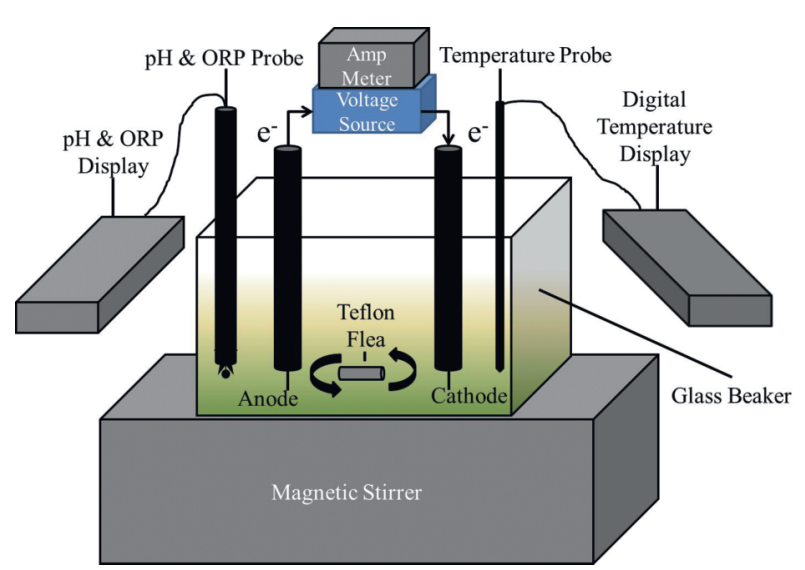

Figure 2: Schematic of electrolysis set-up.

replacement due to susceptibility to clogging. Using membrane-less electrolysis would be one way of producing $\mathrm{ClO}_{2}$ in a simple way, without the requirement of handling hazardous chemicals or operating at extreme conditions by using salt as the electrolyte. The voltage supply is the only required energy supply and could be provided by a cheap, robust solar panel.

A major disadvantage of this process is that not much is known about the production of $\mathrm{ClO}_{2}$ via electrolysis. Due to the resurgence of this old technology, with its possible economic advantages and apparent simplicity, various patents have emerged claiming optimum conditions on generating $\mathrm{ClO}_{2}$. The majority of patents implement a semipermeable membrane that separates the anodic reactions from cathodic ones, giving precise control of product generation (White, 1999). However, these patents, such as EP2305858, claim that a membraneless electrolysis can be setup to produce $\mathrm{ClO}_{2}$ but requires continuous monitoring and operating with additional "exotic" chemicals to keep the electrolyte at a stable $\mathrm{pH}$ to maintain an efficient

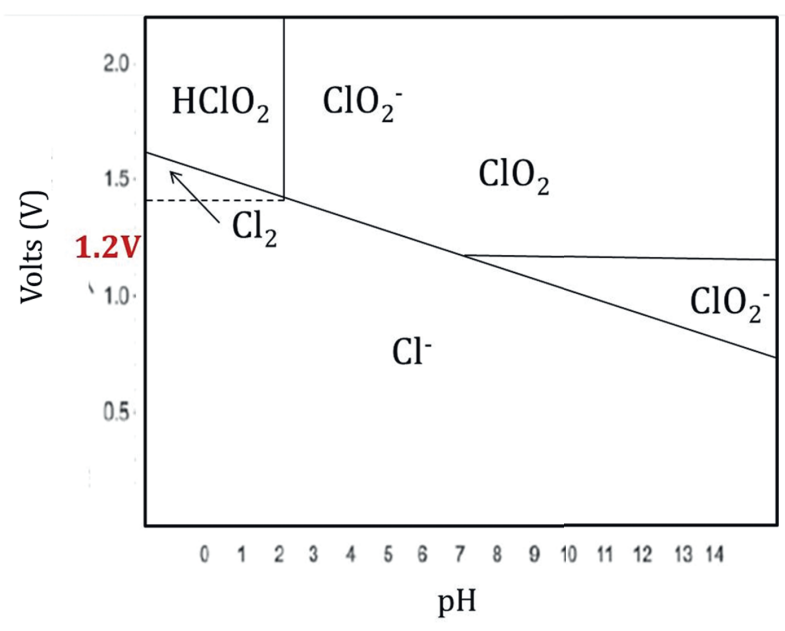

Figure 3: Pourbaix diagram for oxychlorine species (Pourbaix, 1974).

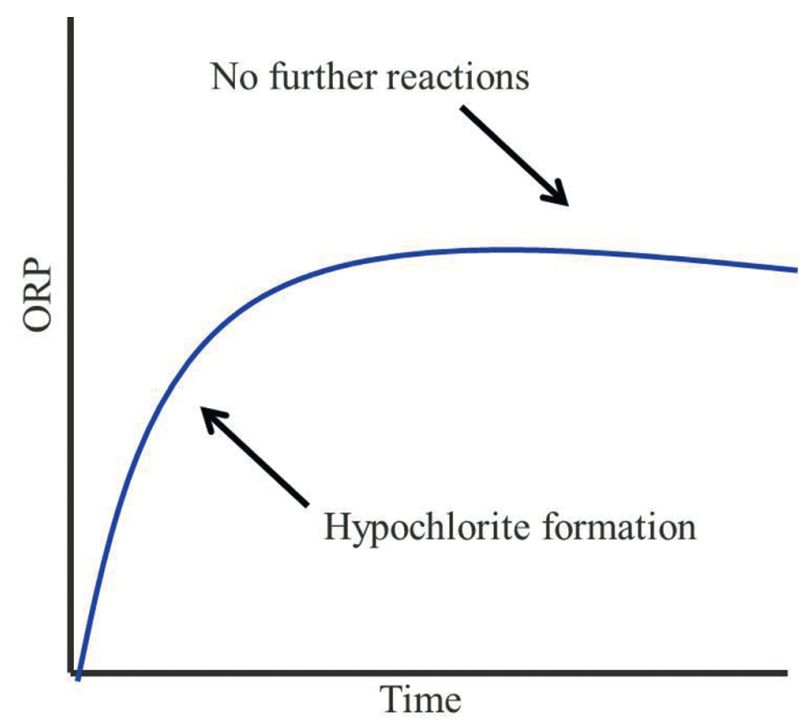

Figure 4: General trend of ORP as a function of time for experiments 1-11.

yield. Furthermore, the feedstock chemical used is usually sodium chlorite in combination with complex chemical buffers. These are not readily obtained in LEDCs thus negating its use for this research; albeit some of the operating conditions and setup are useful in determining conditions for a salt feedstock, which is cheap and readily available.

\section{HYPOTHESIS}

It is proposed that $\mathrm{ClO}_{2}$ production could be achieved via a simple electrolysis arrangement using sodium chloride as the sole feedstock along with cheap and readily available electrode materials to produce $\mathrm{ClO}_{2}$ at safe levels. Distilled water will be used to dissolve the salt, so that any factors from using tap water are eliminated, e.g. dissolved metals affecting $\mathrm{ClO}_{2}$ production. It was decided that the alkaline route would be taken, in order to avoid using acids which are hazardous and not readily available in LEDCs, thus hypochlorite formation in quantities is expected; and the aim is to progress to $\mathrm{ClO}_{2}$ via oxidation reactions.

Upon identification of the procedure's key variables and optimum conditions, one can begin manipulating this process to produce satisfactory concentrations of $\mathrm{ClO}_{2}$ with sufficient oxidising power to meet water disinfection standards.

\section{METHODOLOGY}

\subsection{Apparatus}

The electrolytic cell was composed of a transparent glass beaker containing an electrolytic medium composed of sodium chloride solution made up with distilled water. The anode and cathode were fully 


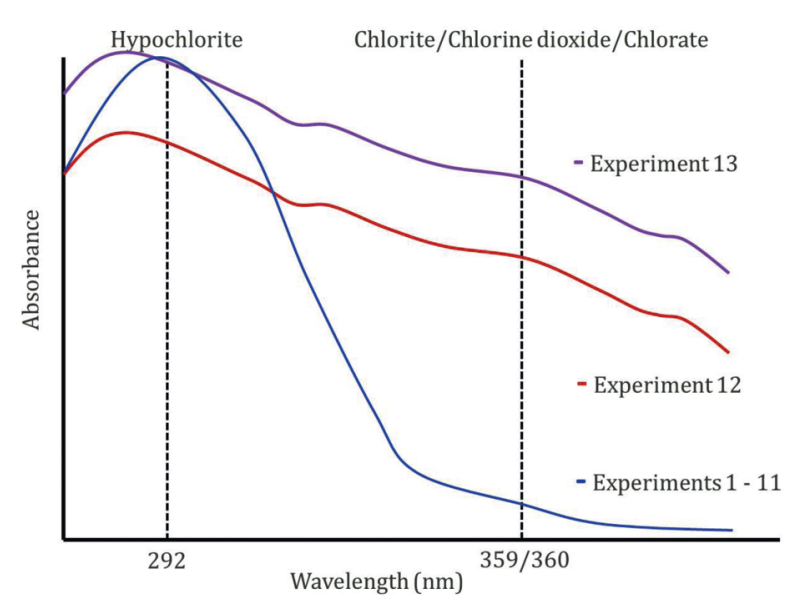

Figure 5: General trend of spectrophotometer results for all experiments.

submerged within the volume of liquid and attached, using crocodile clips, to a voltmeter connected to a mains power supply. The voltmeter was used to observe the relative volts required to achieve the desired current. An additional ammeter was joined in series for an improved accuracy reading of the current being supplied to the cathode. The cell was placed on a magnetic stirrer and a Teflon flea was present within the solution so that constant thorough mixing was achieved. This ensured good mass transfer during the experimentation thus avoiding mass transfer barriers by the accumulation of ions at the electrodes.

Temperature, oxidation-reduction potential (ORP) and $\mathrm{pH}$ probes were placed in the cell for continuous measurements. The duration of the experiment was monitored using a stopwatch and the whole process was contained within a fume cupboard as a safety precaution to minimise possible inhalation of toxic gases.

\subsection{Approach}

A number of variables were tested in order to understand how they influenced the reactions and conditions within the electrolysis cell. Each variable was changed whilst holding all other variables constant so that a clear relationship between the variable and the observed outcome could be made. The $\mathrm{pH}$ and ORP measurements were then used in conjunction with Pourbaix diagrams to determine the presence of different species (Figure 3). This along with spectrophotometer analysis (CARY 3E UVvisible) of aliquots, taken throughout experiments and visual observations were all used to conclude the likely composition of the solution. Each experiment was then used as an indicator as to what approach was to be taken for the subsequent experiment. The following variables were considered in the experiments: current, electrode material and sizing, sodium chloride concentration, volume of electrolytic medium and time.

\section{RESULTS}

Thirteen experiments were conducted in total, with the first eleven carried out in order to gain a rudimentary knowledge on how manipulating variables such as weight of salt, current density and time of electrolysis affected the composition and concentration of the electrolysed solution. The initial eleven experiments used a platinum anode with a stainless steel cathode as recommended by literature to give effective production.

It was established from the initial experiments that hypochlorite was primarily being produced. This was identified by ORP readings levelling off after an initial increase showing no further electron activity (Figure 4) and broad peaks at the characteristic hypochlorite wavelength of absorption, $292 \mathrm{~nm}$ (Figure 5) (WHO). Therefore, it was deemed that an important variable to control was the ORP, as increasing this would increase the electron activity thus permitting higher oxidation states of chlorine to be produced.

It was found from experimental observations and patents that combining a high concentration of salt with a low current density (i.e. low current to electrode surface area ratio) would help to increase the value of the ORP. This low current density would then require a longer experimental time in order for reactions to reach completion. A summary of the experiments conducted can be found in Table 1 .

Experiments 12 and 13 were more refined and used the knowledge from the preceding experiments in attempt to produce the higher oxidation species. This included a ratio of $1 \mathrm{~A} / \mathrm{dm}^{2}$ and $30 \%$ wt salt solution as well as larger electrodes which allowed for a higher current to be used whilst still using a low density, ensuring a high enough reaction rate.

Experiment 12 used two stainless steel electrodes whilst in experiment 13 the cathode was wrapped with aluminium foil. These changes to the electrode material were explored in order to better reflect materials that would be more readily available in LEDCs. The spectrophotometer results show that a much broader peak was observed compared with the initial experiments. Most importantly, this absorbance extended to wavelengths around 360 $\mathrm{nm}$, which indicated the region for $\mathrm{ClO}_{2}$ as well as that of chlorate and chlorite (Figure 6) (WHO). A much higher absorbance was observed when using the aluminium anode, which is due to the higher obtainable potential (and thus concentration of species produced) when using dissimilar electrode materials for the anode and cathode. It must be noted that this observation indicates the possibility but not the confirmation of $\mathrm{ClO}_{2}$ production, further analysis is required (i.e. colorimetric titration).

For experiment 12 , there is an initial drop in $\mathrm{pH}$ (Figure 
Table 1: Summary of all experiments conducted.

\begin{tabular}{|c|c|c|c|c|c|c|c|}
\hline Experiment & $\begin{array}{l}\text { Weight of } \\
\mathrm{NaCl} \\
\text { (g) }\end{array}$ & $\begin{array}{l}\text { Weight } \\
\text { of } \\
\mathrm{NaHCO}_{3} \\
\text { (g) }\end{array}$ & $\begin{array}{l}\text { Volts } \\
\text { (V) }\end{array}$ & $\begin{array}{l}\text { Current } \\
(\mathrm{mA})\end{array}$ & $\begin{array}{l}\text { Volume } \\
\text { of } \\
\text { solution } \\
\quad(\mathrm{ml})\end{array}$ & $\begin{array}{l}\text { Time } \\
\text { (min) }\end{array}$ & $\begin{array}{l}\text { Electrode material } \\
\text { (anode/cathode) }\end{array}$ \\
\hline 1 & 9 & 0 & 2.1 & 2.8 & 90 & 50 & $\begin{array}{c}\text { platinum/nickel coated } \\
\text { stainless steel }\end{array}$ \\
\hline 2 & 0.11 & 0.05 & 10.25 & 100 & 30 & 30 & $\begin{array}{c}\text { platinum/nickel coated } \\
\text { stainless steel }\end{array}$ \\
\hline 3 & 0.11 & 0 & 6 & 50 & 30 & 30 & $\begin{array}{c}\text { platinum/nickel coated } \\
\text { stainless steel }\end{array}$ \\
\hline 4 & 0.11 & 0 & 12.5 & 100 & 30 & 30 & $\begin{array}{c}\text { platinum/nickel coated } \\
\text { stainless steel }\end{array}$ \\
\hline 5 & 0.11 & 0 & 15 & 200 & 30 & 30 & $\begin{array}{c}\text { platinum/nickel coated } \\
\text { stainless steel }\end{array}$ \\
\hline 6 & 0.22 & 0 & 11 & 200 & 30 & 30 & $\begin{array}{c}\text { platinum/nickel coated } \\
\text { stainless steel }\end{array}$ \\
\hline 7 & 0.33 & 0 & 8 & 200 & 30 & 30 & $\begin{array}{c}\text { platinum/nickel coated } \\
\text { stainless steel }\end{array}$ \\
\hline 8 & 0.66 & 0 & 5.9 & 200 & 30 & 45 & $\begin{array}{c}\text { platinum/nickel coated } \\
\text { stainless steel }\end{array}$ \\
\hline 9 & 1 & 0 & 5 & 200 & 30 & 90 & $\begin{array}{c}\text { platinum/nickel coated } \\
\text { stainless steel }\end{array}$ \\
\hline 10 & $\begin{array}{c}0.33 / 0.66 / 0.99 \\
\text { (intermittent } \\
\text { addition) }\end{array}$ & 0 & $8 / 6 / 5$ & 200 & 30 & 90 & $\begin{array}{c}\text { platinum/nickel coated } \\
\text { stainless steel }\end{array}$ \\
\hline 11 & 3 & 0 & 5 & 200 & 90 & 90 & $\begin{array}{c}\text { platinum/nickel coated } \\
\text { stainless steel }\end{array}$ \\
\hline 12 & 27 & 0 & 2.8 & 40 & 90 & 50 & $\begin{array}{c}\text { nickel coated stainless } \\
\text { steel }\end{array}$ \\
\hline 13 & 27 & 0 & 3 & 40 & 90 & 55 & $\begin{array}{l}\text { nickel coated stainless } \\
\text { steel/aluminium foil } \\
\text { wrapped nickel coated } \\
\text { stainless steel }\end{array}$ \\
\hline
\end{tabular}

6a), which indicated the formation of hypochlorous acid from chloride with a corresponding expected increase in ORP. This also coincided with a pale yellow colouration of the solution that is characteristic of hypochlorous acid (Chembase, 2012). There was then a strong increase in $\mathrm{pH}$ and a secondary rise and plateau in ORP along with a dark green colouration after 20 minutes which is indicative of either chlorite or $\mathrm{ClO}_{2}$ (Figure 6b) (Cleartech, 2011).

Experiment 13 (Figure 7a), showed a similar initial trend in both $\mathrm{pH}$ and ORP however, a much higher potential was achieved and there was a noticeable drop in both measurements towards the end of the experiment. This decline could indicate the formation of chlorate, as not only does this form at high potentials but would also cause a corresponding resultant decrease in potential. This decrease in potential is due to its highly stable nature meaning it does not have strong oxidative characteristics. The dark yellow colouring of the solution, Figure $7 \mathrm{~b}$, also indicated chlorate (Cleartech, 2011).

\section{CONCLUSION}

It was found that increasing the weight of salt in the system increased the time required to achieve the same reaction (Experiments 5-9 in Table 1). This variable has been identified as a combination variable, whereby increasing the weight whilst decreasing the current (experiment 11 compared to 12) increases the oxidation potential of the system; which gave the production of chlorite rather than just its precursor, hypochlorite.

As for electrode sizing, a greater electrode surface area endorsed the possibility for a greater potential to be achieved when using a ratio of $1 \mathrm{~A} / \mathrm{dm}_{2}$ (as suggested in patent EP2305858). This is represented when comparing experiments 1 and 12 as despite 


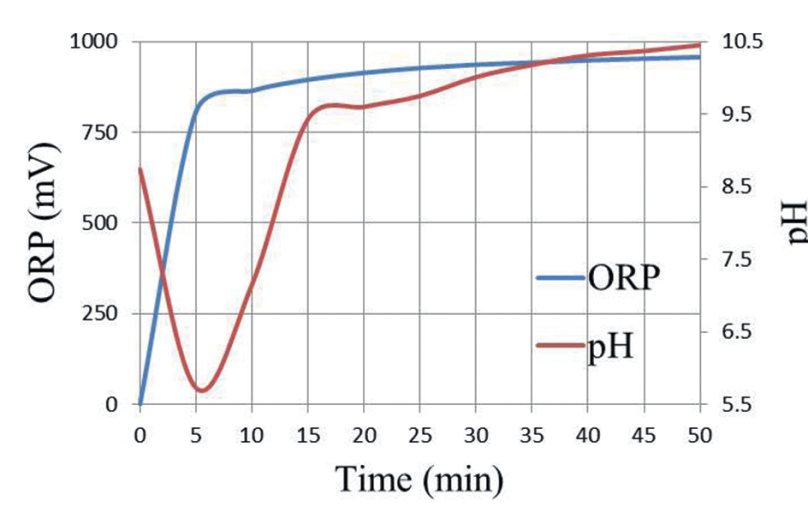

Figure 6a: Experiment 12, $\mathrm{pH}$ and ORP measurements as a function of time.

using the same ratio, experiment 1 used a platinum anode with a smaller surface area than that utilised in experiment 12 , which replaced the platinum electrode with a larger nickel coated stainless steel anode; this increase in anode surface area, and thus current, produced a significantly higher oxidationreduction potential.

The use of different electrode materials gave different ORP values. It was found that using materials that are dissimilar gave a higher possible oxidation potential than using materials that were the same. This was demonstrated in experiment 12 , which had both electrodes made from nickel-plated stainless steel, and experiment 13, where the cathode was wrapped in aluminium foil. Experiment 13 gave a maximum oxidation potential which was $7.7 \mathrm{mV}$ higher than experiment 12. However, using materials further apart in the galvanic series would produce a higher possible potential whilst requiring less voltage in the system (beneficial for a limited volt supply from a cheap solar cell in LEDCs), i.e. aluminium and a metal higher up than stainless steel that has good corrosion-resistant properties. This property would minimise maintenance requirements hence making it viable in LEDCs.

The progression in the experiments conducted proved that it is possible to produce $\mathrm{ClO}_{2}$, but as operating conditions are highly sensitive towards

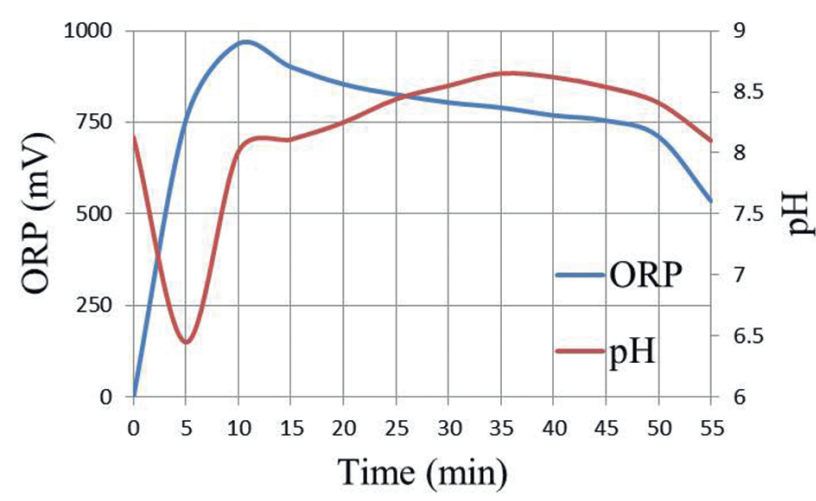

Figure 7a: Experiment 13, $\mathrm{pH}$ and ORP measurements as a function of time.

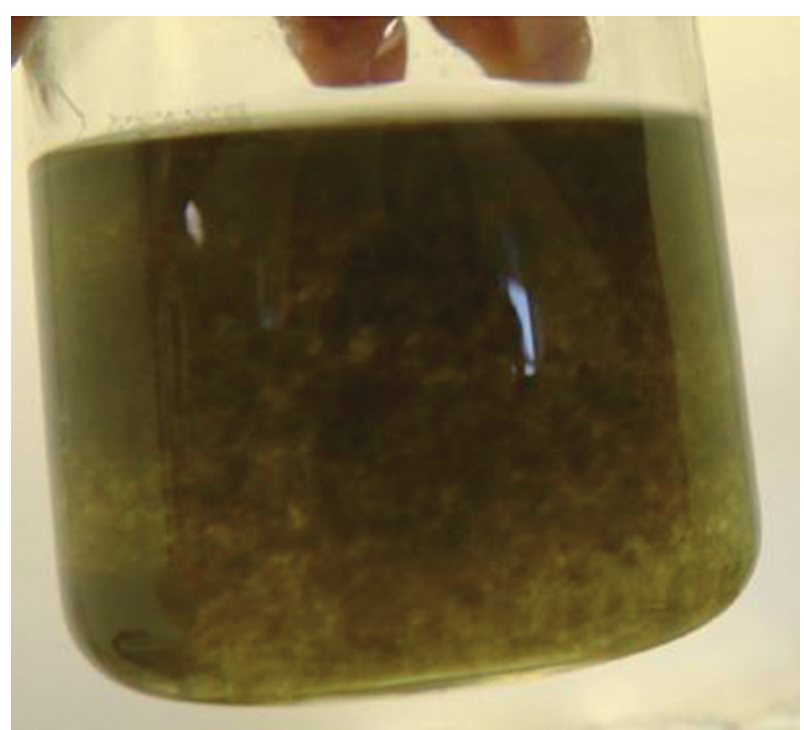

Figure 6b: Photograph of solution from experiment 12 .

reactions that occur and the type of oxychlorine species formed, the variables that were manipulated still require further optimisation and control. Overall, this research has established some of the condition requirements necessary to produce high enough potentials, although further refinement is still required in order to ensure generation of $\mathrm{ClO}_{2}$ which would essentially be somewhere between experiments 12 and 13.

\section{FUTURE WORK}

Despite no definitive generation of $\mathrm{ClO}_{2}$, the use of multiple analysis techniques, in particular methods sensitive to $\mathrm{ClO}_{2}$ such as colorimetric analysis would be valuable in future research analysis. Suggested methods include: methylene blue, N, N-diethyl-p-

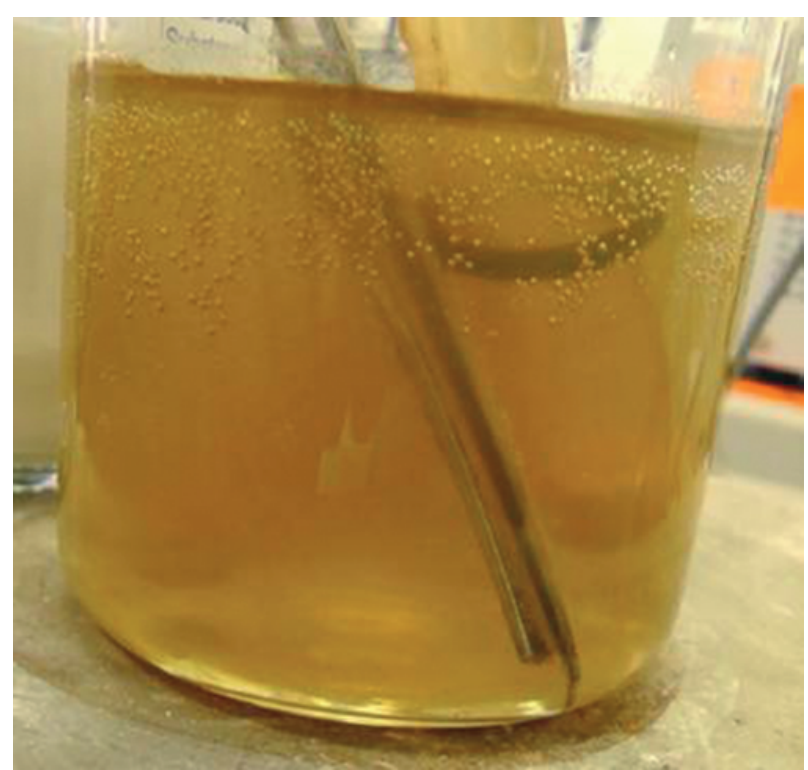

Figure 7b: Photograph of solution from experiment 13. 
phenylenediamine (DPD) in conjunction with oxalic acid and amphoteric titrations via $\mathrm{pH}$ elimination method. Implementing a reliable and robust method of $\mathrm{ClO}_{2}$ detection will ease understanding of the factors that affect $\mathrm{ClO}_{2}$ generation; in future experiments, a direct relationship can be determined between variable manipulation and its effects on $\mathrm{ClO}_{2}$ generation.

Once conditions have been fully optimised for practical field application, additional investigations could then be undertaken into the use of sodium bicarbonate, as this would allow for the possibility of generating the stabilised form of $\mathrm{ClO}_{2}$. It was attempted to use this bicarbonate buffer (Table 1 - experiment 2); however, although successfully stabilising the $\mathrm{pH}$, this made the already restrictive analysis far too complex and did not allow for any comprehensive conclusions to be made, particularly as it interfered with both the visual colour analysis and the spectrophotometer absorbance peaks.

This research delivers the base knowledge to an enticing challenge that, if solved, has the potential to provide millions in LEDCs the access to sanitary water - the basic necessity of life.

\section{ACKNOWLEDGEMENTS}

Special thanks to Prof. Peter Scales and Mr David Parris from the University of Melbourne for their help and guidance.

\section{REFERENCES}

Amundsen, D., 1980. Water Disinfection with Ozone, Chloroamines, or Chlorine Dioxide. In AWWA Seminar Proceedings. Atlanta, 1980. American Water Works Association.

Chembase, 2012. Hypochlorous Acid MSDS. Online Publication, available at: Chembase.

Cleartech, 2011. Material Safety Data Sheet: Sodium Chlorite and Chlorate Solution. Saskatoon, Canada: Cleartech.

Csordas, V., Bubnis, B., Fabian, I. \& Gordon, G., 2001. Kinetics and Mechanism of Catalytic Decomposition and Oxidation of Chlorine Dioixde by the Hypochlorite Ion. Inorganic Chemistry.

EPA, 1999. Alternative Disinfectants and Oxidants Guidance Manual. United States Environmental Protection Agency.

Feachem, R., 1977. Water, Wates and Health in Hot Climates. Sydney: John Wiley \& Sons.

Gates, D., 1998. The Chlorine Dioixde Handbook.
Denver, CO: American Water Works Association.

Gordon, G., Kieffer, R.G. \& Rosenblatt, D.H., 1972. The Chemistry of Chlorine Dioxide. In Progress in Inorganic Chemistry.

Haque, R., 2007. Human Intestinal Parasites. Dhaka, Bangladesh: International Centre for Diarrhoeal Disease Research.

Hoehn, R., Rosenblatt, A. \& Gates, D., 1996. Considerations for Chlorine Dioxide Treatment of Drinking Water. Boston, Massachusetts, U.S.A: American Water Works Association (AWWA) Water Quality Technology Conference.

Hoff, J. \& Geldreich, E., 1980. Water Disinfection with Ozone, Chloroamines, or Chlorine Dioxide. Atlanta, Georgia, U.S.A: American Water Works Association (AWWA) Seminar Proceedings.

Hull, L.A. et al., 1967. Oxidation of Amines III Duality of Mechanism in the Reaction of Amines with Chlorine Dioxide. American Chemistry Society.

Junli, H., Lihua, C. \& Zhenye, Z., 2001. The Pattern of Chlorine Dioxide stabilised by Sodium Carbonate/ Hydrogen Peroxide. Great Britain: Elsevier Science Ltd.

Lonholdt,J., 2005. Water and Wastewater Management in the Tropics. Cornwall: TJ International.

NAP, 2007. Board on Environmental Studies and Toxicology: Acute Exposure Guideline Levels for Selected Airborne Chemicals. Washington DC: The National Academic Press.

Pourbaix, M., 1974. Atlas of Electrochemical Equilibria in Aqueous Solutions. Houston, Texas: National Association of Corrosion Engineers.

Rodgers, A., 2002. The World Health Report: Reducing Risks, Promoting Healthy Life. Geneva: The World Health Organisation.

Ustun, P., 2008. Safer Water, Better Health: Costs, Benefits and Sustainability of Interventions to Protect and Promote Health. Geneva: World Health Organisation.

Vogt, H., Balej, J. \& Bennet, J.E., n.d. Ullmann's Encyclopedia of Industrial Chemistry.

White, G.C., 1999. Handbook of Chlorination and Alternative Disinfectants. Canada: John Wiley \& Sons.

WHO, 2004. Chemistry of Disinfectants and Disinfectant By-Products. Online Publication: The World Health Organisation. 